\title{
Data-driven Design and Curation for Consumer-centric Fast Fashion
}

\author{
Fredrick Shaap* \\ Qiueue Research, USA
}

Submission: September 15, 2020; Published: October 07, 2020

*Corresponding author: Fredrick Shaap, President, Qiueue Research, 401 Congress Ave. Austin, Texas, USA

Abstract

The principles and concepts concerning creation and curation of optimal design for the fast fashion business model are reviewed and discussed briefly. The data-driven, consumer-centric characteristics of these concepts are emphasized and the design process flowcharts for some key examples of related current and popular methodologies are presented and analyzed.

Keywords: Fashion design; Fast fashion; Artificial intelligence; Data analytics; Predictive analytics

\section{Introduction}

The key premise of fast fashion business model and the respective supply chain is the design, development, production and merchandising of on-trend and high-value products at a rapid rate [1]. Among all these factors, the element of design is of paramount importance due to the fact that ultimately the consumer must like and desire a particular article of fashion, which its purchase will support the respective business model. Additionally, the underlying creative process must be responsive to the data, which is reflective of the current trends, popular demand, seasonality, operational limits, cost-effectiveness, etc. Therefore, holistically, one could refer to this concept as data-driven, consumer-centric fashion design (D2C2-FD). In principle, the D2C2-FD concept seeks to create fast fashion products that not only satisfy the needs and desires of the consumer but also generate a profitable and sustainable revenue stream for the brand. Furthermore, an optimal implantation of the D2C2-FD concept will minimize the merchandise liquidation and waste due to overstock inventory.

To a varying degree in sophistication and complexity, every major participant in the fast fashion industry has developed and utilizes a D2C2-FD methodology. From extracting browsing data on popular social media platforms to their own internal sales statistics, these companies have devised effective predictive analytics to identify the main optimal design attributes in each product category, including: apparel, footwear, sportswear, accessories, jewelries, etc. In some cases [2], a framework consisting of artificial intelligence, machine-learning and data analytics combined with expert curation creates the most optimal design for its intended purpose. In the following, a number of popular D2C2-FD methodologies are reviewed and discussed briefly.

\section{Methodologies}

Figure 1 shows the design process flowchart for a basic D2C2FD methodology, in which, for a targeted product, a combination of internal sales data (customer preferences, inventory statistics, customer feedback) and external trend data (social media sentiment, current trends) is used to produce a preliminary optimal set of design variants. Subsequently, this initial set is down selected to a qualified final design based on expert curation. The specific sources of data and their analyses may vary; however, the logic behind the process remains the same in principle.

Figure 2 shows the design process flowchart for an esoteric D2C2-FD methodology, which combines data analytics within an artificial intelligence framework and expert curation to produce the ideal design variant(s). The data comprises the input set of global style trends (also known as mode analysis), social media consensus (aka media analysis) and relevant market insights (aka market analysis). The guidance from the analysis of this data drives the design development process, which consists of generative design synthesis (aka iterative design creation), algorithmic design optimization (aka parametric design augmentation), and hybrid design curation (expert-assisted design derivation) as carried out by the designer(s). 
Figure 3 shows the design process flowchart for a mutative D2C2-FD methodology, in which, a detailed taxonomy of the design elements is utilized to define and synthesize an optimal combination of such elements to produce new variants of existing popular designs. The overall optimization process is stochastic and based on principles of genetic algorithms. The steps involved include algorithmic selection, algorithmic recombination and algorithmic mutation leading to new designs, which are subsequently curated by the fashion designer(s) to produce a set of new optimal designs.

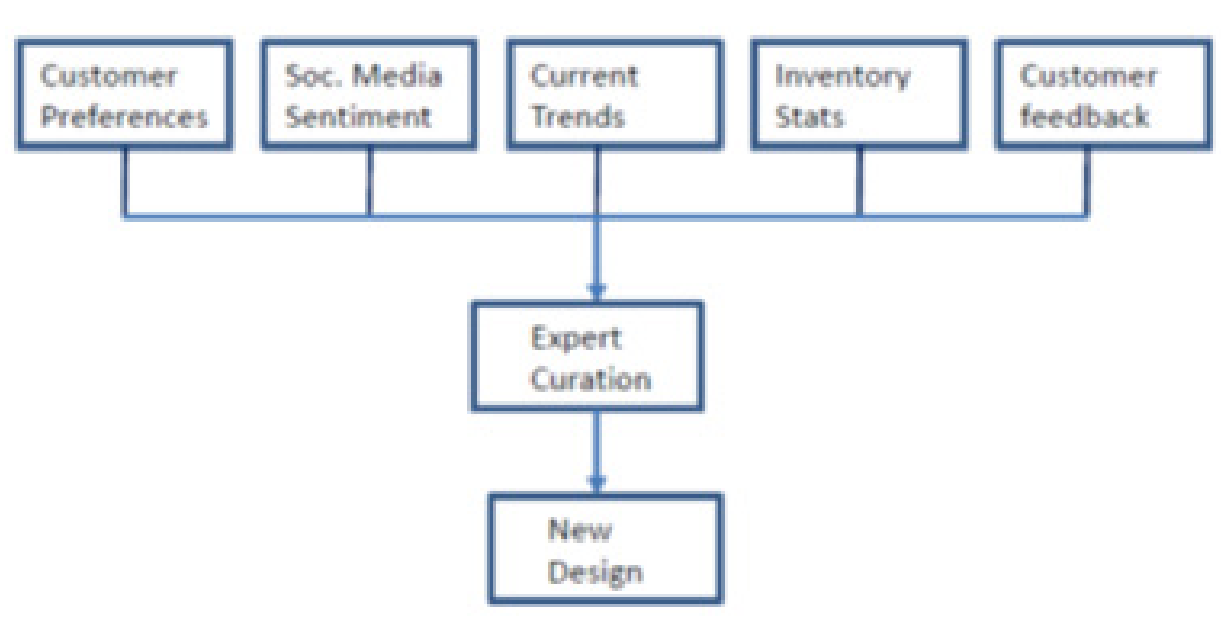

Figure 1: Process flowchart for basic D2C2-FD methodology.

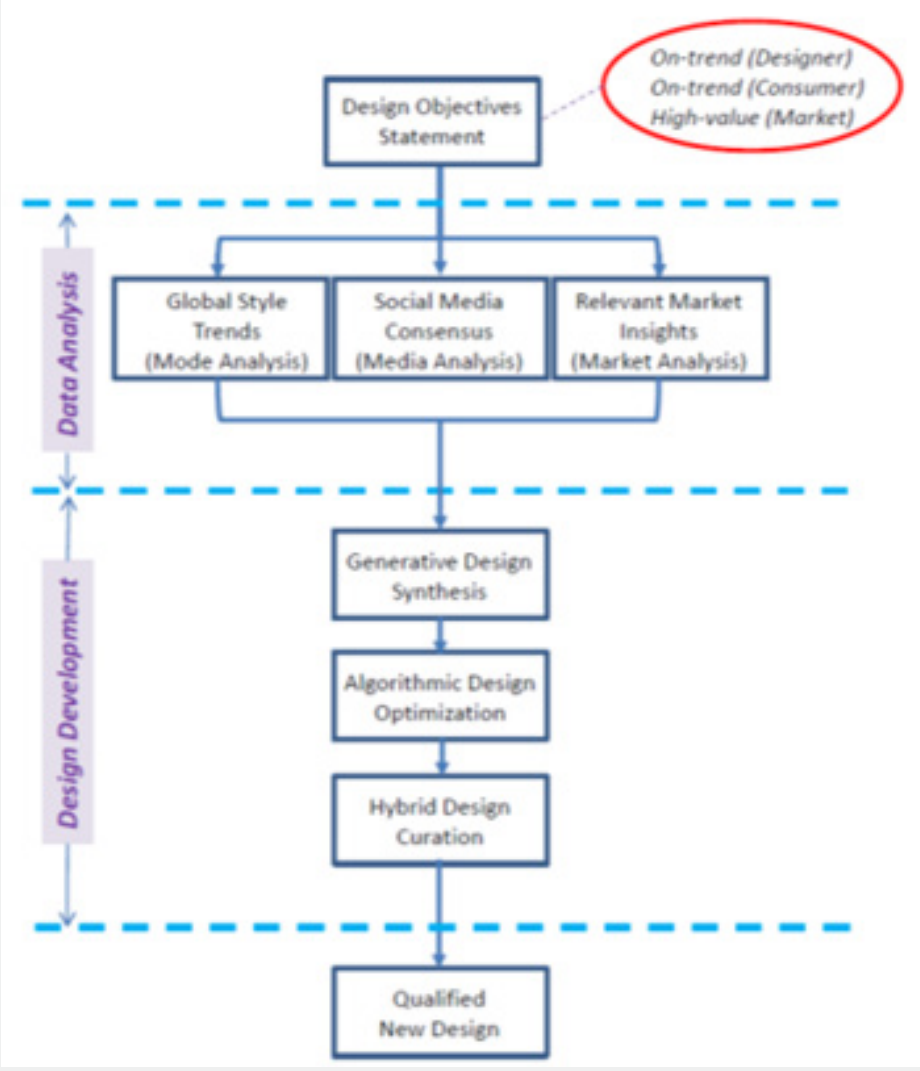

Figure 2: Process flowchart for esoteric D2C2-FD methodology. 


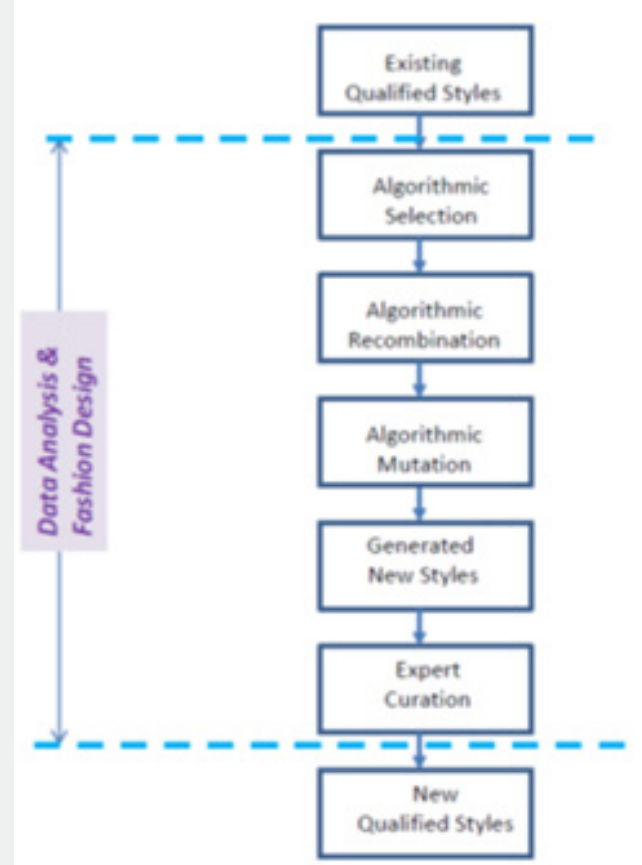

Figure 3: Process flowchart for mutative D2C2-FD methodology.

Figure 4 shows the design process flowchart for an iterative D2C2-FD methodology, which uses a three-step process to generate new qualified designs for its brand within the specified category. The customers' desirements, in terms of style preferences, initiates the first main step of the process, which consists of trend analysis based on global fashion trends as well sales statistics extracted from real-time sales activity. The conclusions from this step are compared and contrasted against those based on social media consensus to identify the common attributes for new designs during the second step of the process. Finally, assisted by the fashion designer(s), a set of new designs are developed and qualified iteratively to result in new style sets and/or produce complementary style assortments.

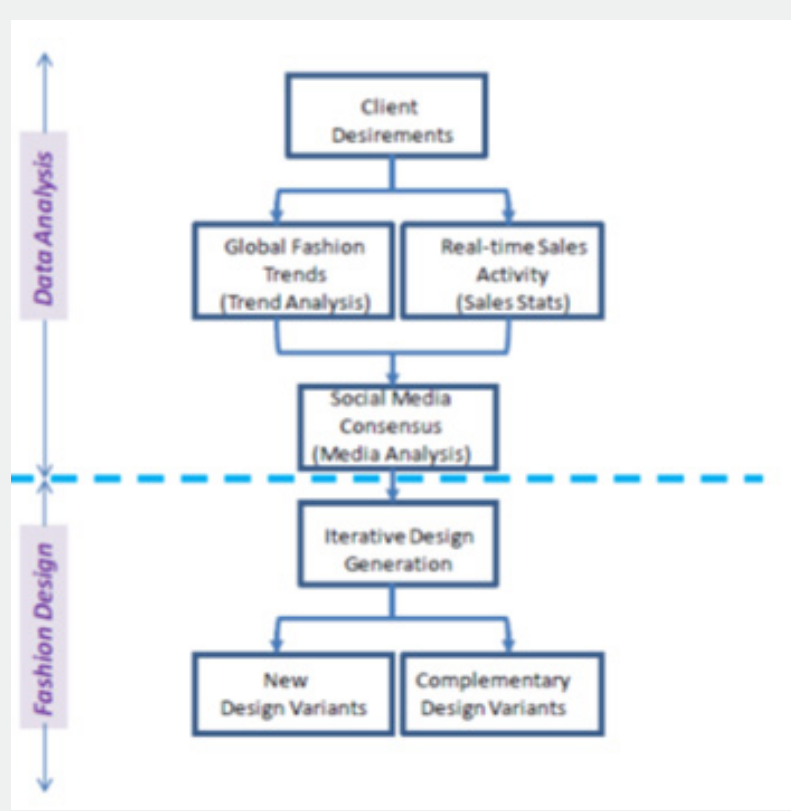

Figure 4: Process flowchart for iterative D2C2-FD methodology. 


\section{Conclusion}

Data-driven, consumer-centric design process is an integral and critical element of the fast fashion concept. Although a variety of methodologies are employed to accomplish this task, the objective remains the same, that is, creation of optimal on-trend and high-value products for the consumer using the relevant data sets.

\section{References}

1. Caro F, de Albéniz VM (2015) Fast Fashion: Business Model Overview and Research Opportunities. In: Agrawal N, Smith S (Eds.), Retail Supply Chain Management. International Series in Operations Research \& Management Science, Springer, Boston, Massachusetts, USA, p. 223.

2. Shaap F (2020) Artificial Intelligence for Fashion Design. Curr Trends Fashion Technol Textile Eng 6(3): 555697.

\section{Your next submission with Juniper Publishers} will reach you the below assets

- Quality Editorial service

- Swift Peer Review

- Reprints availability

- E-prints Service

- Manuscript Podcast for convenient understanding

- Global attainment for your research

- Manuscript accessibility in different formats ( Pdf, E-pub, Full Text, Audio)

- Unceasing customer service

Track the below URL for one-step submission https://juniperpublishers.com/online-submission.php 